DMARD for at least three months. Only anti-TNFs were used as a first line b-DMARD therefore secukinumab (Secu) was used after first line b-DMARD treatment. Adalimumab, certolizumab, etanercept, golimumab were grouped as subcutaneous (s.c) anti-TNFs. MDA was defined as meeting five out of seven criteria during follow-up [1]. Results: One hundred seventy-two patients ( $61 \%$ female) were included into the analysis. The mean follow-up time was $105.4 \pm 76$ (6-444) months and the mean age was $50.2 \pm 13.3$ (16-81) years. Mean age of onset for PsA was $38 \pm 11.9$ (1179) years; mean PsA and PsO duration were $140 \pm 90.7$ (7.9-528) and $253 \pm 138$ (0-756) months, respectively. Methotrexate was the most commonly used ( $88 \%)$ CS-DMARD and biological DMARDs were used in 74 patients (43.3\%)

Overall, 95 patients (55.2\%) were observed at MDA which was significantly lower in b-DMARD users compared to only cs-DMARD users (45.9\% vs $61.9 \%$; $p=0.038$, OR: 4.3). MDA did not differ according to PsA subtypes. The addition of cs-DMARD treatment to $b$-DMARDs did not affect MDA frequency In univariate analysis; higher MDA frequency was associated with older age $(p=0.002)$, longer PsO duration $(p=0.036)$, late onset of PsA $(p=0.007)$ and continuation of first b-DMARD (OR:13.9 p<0.001). In multivariate analysis, older age (OR:1.3;95 \% $\mathrm{Cl}: 1.02-1.68$ ), late onset PsA (OR:1.03; $95 \% \mathrm{Cl}: 1.01-1.067)$ and continuation of first b-DMARD (OR:46.8; $95 \% \mathrm{Cl}: 1.6-1371$ ) were associated with MDA.

Conclusion: Although frequency of MDA in our cohort was consistent with previous reports, a significant number of patients could not achieve MDA. Frequency of MDA was found to be lower in b-DMARD users compared to cs-DMARD users, possibly resulted from initiation of b-DMARD in patients with higher disease activity. Higher MDA rate was associated with higher continuation rate at first line b-DMARD treatment (TNF-inhibitor) and decreased gradually after b-DMARD switches. Although combined use of cs-DMARD with b-DMARDs did not increase the frequency of MDA, it was associated with higher b-DMARD retention. MDA is a useful outcome measure in daily follow-up of PsA patients and the importance of reaching sustained MDA for prognosis should be investigated further. REFERENCES:

[1] Coates, L.C., J. Fransen, and P.S. Helliwell, Defining minimal disease activity in psoriatic arthritis: a proposed objective target for treatment. Ann Rheum Dis, 2010. 69(1): p. 48-53.

Table 1. b-DMARD responses, continuation rate and frequency of achieving MDA in patients with PsA

\begin{tabular}{|c|c|c|c|c|c|}
\hline b-DMARD treatment & $\begin{array}{l}\text { Mean (median) } \\
\text { duration (month) }\end{array}$ & $\begin{array}{l}\text { Continuation } \\
\text { rate } n,(\%)\end{array}$ & $\begin{array}{c}\text { Primary } \\
\text { inefficacy } \\
n,(\%)\end{array}$ & $\begin{array}{c}\text { Secondary } \\
\text { inefficacy } \\
n,(\%)\end{array}$ & $\begin{array}{r}\text { MDA } \\
n,(\%)\end{array}$ \\
\hline First line b-DMARD $(n=74)$ & $50.4(36)$ & $37(50)$ & $9(24.3)$ & $17(46)$ & $\begin{array}{c}34 \\
(45.9)\end{array}$ \\
\hline $\begin{array}{l}{ }^{*} \text { S.c TNF inhibitors } \\
(\mathrm{n}=62 ; 83.8 \%)\end{array}$ & $50.8(35.5)$ & $32(51.7)$ & $8(26.7)$ & $9(30)$ & $31(50)$ \\
\hline Infliximab (n=12; $16.2 \%)$ & $13.8(11)$ & $3(25)$ & $1(11.1)$ & $7(77.8)$ & $3(25)$ \\
\hline Second line b-DMARD $(n=29)$ & $28.4(13.5)$ & $15(51.7)$ & $5(35.7)$ & $3(21.4)$ & $8(27.6)$ \\
\hline $\begin{array}{l}{ }^{*} \text { S.c TNF inhibitors } \\
(\mathrm{n}=22 ; 75.9 \%)\end{array}$ & $28.6(15)$ & $11(50)$ & $4(36.4)$ & $2(18.2)$ & $5(22.7)$ \\
\hline Infliximab ( $\mathrm{n}=5 ; 17.2 \%)$ & $35.2(36)$ & $3(60)$ & - & - & $2(40)$ \\
\hline Secukinumab ( $n=2 ; 6.9 \%)$ & $9(9)$ & $1(50)$ & $1(50)$ & - & $1(50)$ \\
\hline
\end{tabular}

s.c:subcutaneous

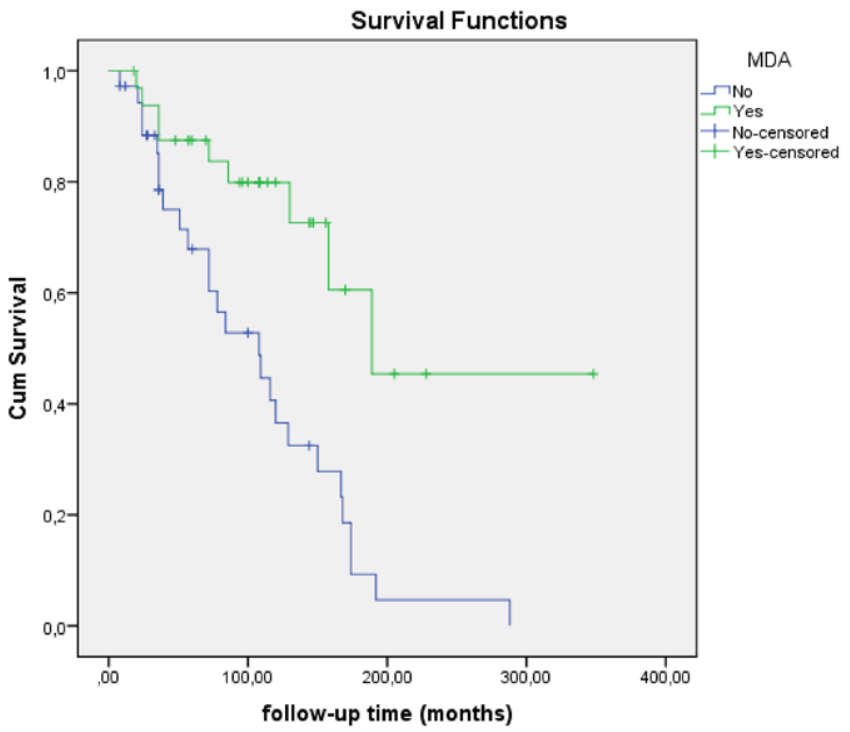

Figure 1. Comparison of b-DMARD retention according to MDA status in patients with ongoing first line $b$-DMARD treatmentLog rank: $p=0.001$
Disclosure of Interests: None declared

DOI: 10.1136/annrheumdis-2021-eular.714

\section{POS0143 ACHILLES TENDON IS USEFUL TO DIFFERENCIATE PSORIATIC ARTHRITIS FROM THE PHYSIOLOGICAL ADAPTATION TO EXERCISE}

C. Guillén-Astete ${ }^{1}$, V. García García2, N. García-Montes ${ }^{1}$, Á. Andreu-Suárez ${ }^{1}$ ${ }^{1}$ Hospital Ramón y Cajal, Rheumatology, Madrid, Spain; ${ }^{1}$ Hospital Ramón y Cajal, Rheumatology, Madrid, Spain

Background: Achilles enthesitis is the most accessible psoriatic arthritis hallmark to assess through ultrasound scan. Recently it has been demonstrated that continuous mechanical stress such as experimented by runners can drive to the development of physiological morphological changes that resembles those observed in psoriatic arthritis. In a subject with the suspicious diagnostic of psoriatic arthritis who practice any sports associated to continuous impact over the heels, the challenge to determine in what extent the morphological changes are linked to the exercise or to the disease, is remarkable.

Objectives: To determine morphological differences between patients with psoriatic arthritis, trained runners and sedentary volunteers through ultrasound scan of the Achilles tendon.

Methods: An ultrasound scan of the Achilles tendon was performed to the following subjects: Patients with diagnosis of psoriatic arthritis with a DAPSA score of low activity in at least six months and with history of heel pain in the past, volunteers runners with not less of 3-year sport activity at least three times a week and sedentary volunteers. In the group of patients, ultrasound scan was performed over the feet with history of heel pain. In the case of volunteers, the ultrasound scan was performed in the dominant feet. The selection of volunteers was not randomly-based in order to match their age and sex to the patients as much as possible. Besides demographic features, a comparison between tendon thickness at the level of the calcaneus bone border and the height of the retrocalcaneus bursae in the longitudinal axis were performed through ANOVA test. Power Doppler signal was scaned in all subjects before and after a controlled mechanical stress of the Achilles tendon by climbing stairs (100 steps, two times).

Results: Female/male distribution of the group of patients, runners and sedentary people were: $12 / 10,18 / 18$ and $20 / 18$, respectively. Achilles tendon mean thickness \pm standard deviation was $6.61 \pm 1.05,5.91 \pm 1.44$ and $4.61 \pm 2.1 \mathrm{~mm}$, respectively $(P=0.01)$. Retrocalcaneus bursae height was $3.42 \pm 0.21,3.22 \pm$ 0.27 and $2.21 \pm 0.31(P=0.01)$. Basal PD signal was present into the enthesis of $2 / 22,1 / 36$ and $0 / 38$, respectively ( $P$ not significant). After exercise, $P D$ signal was present in $8 / 22,5 / 36$ and $0 / 38$, respectively $(P<0.001)$.

Conclusion: Power Doppler signal after exercise was identified as the most relevant ultrasound hallmark to distinguish a patient with psoriatic arthritis from a trained runner, even when psoriatic arthritis were considered as low activity. Post exercise ultrasound scan should be considered as a diagnosis tool in sportsmen with suspicious of psoriatic arthritis, until further studies confirm our findings. Disclosure of Interests: None declared DOI: 10.1136/annrheumdis-2021-eular.3897

\section{POS0144 \\ NOVEL APPLICATION OF OPTICAL COHERENCE TOMOGRAPHY ANGIOGRAPHY AND NAILFOLD CAPILLAROSCOPY IN PSORIATIC ARTHRITIS - DIAGNOSTIC AND PROGNOSTIC ACCURACY IN RELATION TO PSORIASIS AND HAND OSTEOARTHRITIS}

J. Guldberg-Møller ${ }^{1,2}$, T. Schjødt Jørgensen ${ }^{1}$, M. Henriksen ${ }^{1}$, K. Ellegaard ${ }^{1}$, M. Mogensen ${ }^{3}$, L. E. Kristensen ${ }^{1} .{ }^{1}$ The Parker Institute, University Hospitals of Copenhagen, Bispebjerg and Frederiksberg, Copenhagen F, Denmark; ${ }^{2}$ Slagelse Sygehus, Zealand University Hospitals, Slagelse, Denmark

${ }^{3}$ University Hospitals of Copenhagen, Bispebjerg and Frederiksberg, Department of Dermatology, Copenhagen F, Denmark

Background: Nailfold video capillaroscopy (NVC) and angiographic optica coherence tomography (OCTA) have potential in diagnosing psoriatic arthritis (PsA) and differentiating it from psoriasis vulgaris ( $\mathrm{PsO})$ and hand osteoarthritis $(\mathrm{OA})$

Objectives: To assess the diagnostic properties of NVC and OCTA in patients with PsA compared to patients with $\mathrm{PsO}$ and hand OA based on nailfold capillary patterns.

Methods: Patients with distal interphalangeal-joint PsA and nail involvement $(n=50)$, PsO with nail involvement $(n=12)$; and OA $(n=13)$ were included in this cross-sectional study. Capillaries were evaluated semi-quantitatively and qualitatively. Differences in capillary findings between groups were assessed using 